\section{NOVA TELLVS}

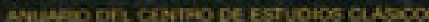

Nova Tellus

ISSN: 0185-3058

novatelu@servidor.unam.mx

Centro de Estudios Clásicos

México

Beuchot, Mauricio

Perfil del pensamiento filosófico de fray Alonso de la Vera Cruz

Nova Tellus, vol. 29, núm. 2, 2011, pp. 201-214

Centro de Estudios Clásicos

Distrito Federal, México

Disponible en: http://www.redalyc.org/articulo.oa?id=59122571008

- Cómo citar el artículo

- Número completo

- Más información del artículo

Página de la revista en redalyc.org

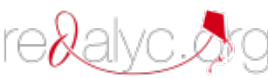

Sistema de Información Científica

Red de Revistas Científicas de América Latina, el Caribe, España y Portugal

Proyecto académico sin fines de lucro, desarrollado bajo la iniciativa de acceso abierto 


\title{
Perfil del pensamiento filosófico de fray Alonso de la Vera Cruz
}

\author{
Mauricio BEUCHOT \\ Universidad Nacional Autónoma de México \\ mbeuchot50@gmail.com
}

RESUMEN: En este artículo se busca ofrecer una panorámica sobre la filosofía de fray Alonso de la Vera Cruz, uno de los primeros agustinos españoles que vinieron a enseñar en la Nueva España (s. XVI). Su enseñanza filosófica abarca la lógica, la física y la ética social. La lógica y la física componen su curso de filosofía, el primero en el Nuevo Mundo, publicado en la imprenta de Juan Pablos en 1554. La ética social se puede rastrear en sus obras De dominio infidelium, Speculum coniugiorum y otras. Enseñó en colegios de su orden, que él mismo fundó, y en la naciente Universidad mexicana. Su docencia estuvo a la altura de los mejores de Europa.

\section{Friar Alonso de la Vera Cruz, Philosophical Thought Profile}

ABSTRACT: This article aims at giving an overview over the philosophy of Friar Alonso de la Vera Cruz, one of the first Spanish Augustinian monks who came to New Spain $\left(16^{\text {th }} \mathrm{c}\right.$.) as a teacher. His philosophical teaching spans logic, physics and social ethics. His philosophy course, the first in the New World, was dedicated to logic and physics and was printed by Juan Pablos in 1554. His social ethics can be found in his works De dominio infidelium, Speculum coniugiorum amongst others. He taught in the Augustinian colleges founded by him, as well as in the newly created Mexican University. His teaching was on a par with that of the best European scholars.

Palabras Clave: Alonso de la Vera Cruz, filosofía en la Nueva España, agustinos, primer curso de filosofía en el Nuevo Mundo.

Keywords: Alonso de la Vera Cruz, Philosophy of New Spain, Augustinian order, first philosophy course in the New World.

FECHA DE RECEPCIÓN: 4 de junio de 2011.

FECHA DE ACEPTACIÓN: 6 de octubre de 2011. 


\title{
Perfil del pensamiento filosófico de fray Alonso de la Vera Cruz
}

\author{
Mauricio BEUCHOT
}

\section{Introducción}

Fray Alonso de la Vera Cruz fue uno de los pioneros de la vida filosófica en la Nueva España. En muchos sentidos fue un fundador de la intelectualidad en México. Fundó escuelas y bibliotecas, fue uno de los primeros profesores en la recién creada Universidad, y para ella escribió el primer curso filosófico de este Nuevo Mundo. De ahí que merezca un lugar privilegiado en la historia de la filosofía novohispana.

Daremos, en primer lugar, un breve esbozo biográfico. Luego señalaremos sus obras principales, las que más repercusión tuvieron en los estudiosos de la Colonia. Con posterioridad hablaremos de su trabajo en el campo de la lógica, donde fue excelente. Después, sobre sus estudios de física, en la que también se distinguió. Y, finalmente, acerca de su pensamiento filosófico-jurídico, el cual fue igualmente notable. Con ello tendremos un panorama de la labor filosófica de este prócer de nuestra cultura patria.

\section{Esbozo biográfico}

Alonso (a veces llamado también Alfonso o Ildefonso) Gutiérrez vio la luz primera en Caspueñas, Toledo (España), en 1507. Hizo estudios de gramática y retórica en la Universidad de Alcalá de Henares, después de lo cual pasó a estudiar artes (esto es, filosofía) y teología en la Universidad de Salamanca. En ella recibió el grado de Maestro en teología. En esta última universidad tuvo profesores tan célebres como los dominicos Francisco de Vitoria y Domingo de Soto, quienes lo condujeron hacia la filosofía tomista, y allí mismo fue, además, catedrático de artes.

Fue ordenado sacerdote en el clero secular, y ya era un profesor joven muy prometedor, cuando cambió su camino. Tenía mucho futuro tanto en el plano académico como en el material, pues su talento lo recomendaba 
ante personajes prominentes, que pensaban en él para cargos importantes y buenas prebendas. Pero prefirió acompañar a un grupo de agustinos que iban hacia México a evangelizar. Como éstos no tenían a alguien de su propia orden que los acompañara para enseñar a los que ingresaban, invitaron a Alonso para que fuera su maestro de teología en esa tierra donde aún no tenían ninguno. Por eso, en 1536 abandona su brillante carrera y se traslada a la Nueva España para ser profesor de los agustinos; y no sólo eso, sino que toma el hábito de ellos al llegar allá, en el puerto de Veracruz, por causa de lo cual añade a su nombre el de ese lugar.

Fray Alonso fue profesor de artes y teología en colegios que fundó y promovió, como los de Tiripetío (1540), Tacámbaro (1545), y Atotonilco el Grande (1546). En 1553 fue también uno de los primeros profesores de la recién fundada Universidad de México, donde enseñó Sagrada Escritura y Teología escolástica, y el primero en publicar un curso de filosofía. Sus obras filosóficas, las primeras editadas en el Nuevo Mundo, se publicaron en México en 1554 y 1557. Tras muchos años en que promovió los estudios filosóficos y teológicos, murió en la Nueva España en 1584. ${ }^{1}$

\section{Obra filosófica}

De la pluma de fray Alonso surgió lo que con todo derecho debe llamarse el primer curso filosófico del Nuevo Mundo. En él abarca la lógica menor, la lógica mayor y la física en el sentido aristotélico. A ello se añade su obra filosófico-jurídica, desplegada en varios volúmenes.

En el curso de fray Alonso, la parte lógica y física comprende tres obras principalísimas, que son la Recognitio summularum, la Dialectica resolutio y la Physica speculatio. ${ }^{2}$ Esto constituye su producción estrictamente filosófica. ${ }^{3}$ Dejó otros escritos pertenecientes a diversos campos,

\footnotetext{
${ }^{1}$ Véase P. Cerezo de Diego, 1985.

${ }^{2}$ Las ediciones son las siguientes: Recognitio summularum reverendi patris Illdephonsi a Vera Cruce..., Mexici, Ioannes Paulus Brissensis, 1554, 1562 (Salamanca), 1569, 1573 у 1579 (hipotética); Dialectica resolutio cum textu Aristotelis edita per reverendum patrem Alphonsum a Vera Cruce..., Mexici, Ioannes Paulus Brissensis, 1554, 1562 (Salamanca), 1569 y 1573; Physica speculatio, aedita per R. P. F. Alphonsum a Vera Cruce... Accessit compendium spherae Campani ad complementum tractatus de coelo..., Mexici, Ioannes Paulus Brissensis, 1557, 1562 (Salamanca), 1569 y 1573. En las ediciones españolas no figura el compendio de Campano.

${ }^{3}$ Véase W. Redmond, 1972, p. 105.
} 
que son igualmente apreciables. ${ }^{4}$ Más adelante consideraremos algunos trabajos suyos, relativos a la filosofía jurídica, acerca de la conquista, que pueden verse como valiosas aplicaciones prácticas de una inteligencia altamente especulativa. Y es que fue sin duda el autor que más se dedicó a formar el pensamiento mexicano en sus orígenes, de manera incansable y con una doctrina muy sólida. ${ }^{5}$ Veamos su pensamiento lógico, físico y jurídico por orden.

\section{La lógica}

La lógica ocupa un lugar muy importante en el pensamiento de fray Alonso. De las obras anteriormente mencionadas, hemos de señalar las dos primeras como dedicadas a este tema de la lógica; son las que llevan por título Recognitio summularum y Dialectica resolutio.

La Recognitio summularum recibía ese nombre porque era una revisión o depuración de las súmulas o compendios de lógica. Era la lógica formal, y, aun cuando abarcaba los elementos introductorios a dicha materia, tenía tratados notables, muy semejantes a los que se enseñan hoy en día en los cursos normales de lógica contemporánea. ${ }^{6}$

La depuración que Alonso hace de la lógica menor consiste en sacar de ella lo que resultaba inútil y desubicado o desproporcionado en el ámbito de la lógica formal. Llega a una enseñanza sobria pero suficiente. Así, en el tratado de los términos y sus propiedades lógicas expone los aspectos principales de la teoría de la significación y la suposición, que corresponden al sentido y a la referencia o significado. Hace una exposición muy competente de esta doctrina medieval. La suposición era el instrumento lógico-semántico con que los escolásticos (medievales y posmedievales) reconocían el tipo de referencia que tenía un término en la proposición o enunciado. Había varios tipos de suposición: material o metalingüística, como en "Hombre es bisílabo", donde el término hombre se supone por sí mismo como término, y con eso se marcaba que el vocablo se mencionaba, que no se usaba, o que estaba en un nivel de metalenguaje. Otra era la suposición formal simple, como en "El hombre es una especie", donde hombre tenía como referencia un concepto o naturaleza común, y no se confundía

\footnotetext{
${ }^{4}$ Véase A. Bolaño e Isla, 1947.

${ }^{5}$ Véase J. M. Gallegos Rocafull, 1974, pp. 276 ss.; 1973, p. 134.

${ }^{6}$ Para una reconstrucción de la lógica formal de fray Alonso con instrumentos de la lógica actual, véase W. Redmond y M. Beuchot, 1985, p. 37 ss.
} 
con "El hombre tiene raciocinio", donde dicho vocablo tiene suposición personal y se supone por los individuos, no por esencias ni por conceptos ni por palabras. Esta teoría de la suposición servía para determinar la extensión de los términos, y a veces su intensión o comprensión; también se utilizaba para controlar la cuantificación de los mismos y para asegurar la validez de las inferencias por el análisis clarificador de los términos que figuraban en ellas. La competencia lógica de fray Alonso se trasluce en el tratamiento que hace de las suposiciones de los términos con cuantificadores especiales, en proposiciones analizables (a las que se llamaba exponibles o resolubles), por ejemplo, en casos difíciles como el de la cuantificación de las proposiciones "El caballo de todo hombre corre", "Algún hombre, en cuanto es todo pensante en una habitación, es alguien que reflexiona”, etcétera.

En la lógica de predicados, Alonso emplea nuevos signos de cuantificación o cuantificadores, que ya usaban los lógicos nominalistas, de quienes los toma, y que muchos autores posteriores a él no llegan a introducir ni a comprender adecuadamente. Utilizaba innovaciones convenientes para la lógica formal, aportadas por los excelentes lógicos nominalistas medievales y posmedievales, aunque no adoptara sus posturas ontológicas o metafísicas. En su lógica cuantificacional, Alonso exhibe numerosas ampliaciones de la cuantificación de los predicados, conocida hoy como cuantificación múltiple. Eso contradice a lógicos modernos, como Hamilton y otros, que negaban la cuantificación de los predicados en la escolástica.

La lógica proposicional de Alonso contiene tratados sobre las proposiciones hipotéticas, de las que aporta las tablas veritativo-funcionales de manera muy parecida a como se hace ahora, siguiendo la tradición estoica. Por otra parte, al hablar de la argumentación, no se reduce a la silogística aristotélica, al modo como se ha dicho de algunos casos de la escolástica posterior, sino que encuentra vertebración en la doctrina general de la inferencia o consequentia, de origen estoico, y que se ampliaba a múltiples campos, entre ellos al de la lógica modal. Por dar un ejemplo, en la lógica modal tiene clarificadoras distinciones para operar con proposiciones modales de re sin confundirlas con las de dicto, ni tener que reducirlas a ellas, cosa ahora muy estudiada. Y, como lo ha mostrado Redmond, fray Alonso tiene, además, algunos avances en la línea de la lógica de relaciones. ${ }^{7}$ En todo ello, Alonso se muestra como gran conocedor de

${ }^{7}$ W. Redmond, 1984, pp. 23-41. 
las ideas lógicas de su tiempo y como un lógico muy completo, que en muchas cosas sentimos como un colega.

Por otra parte, en la lógica mayor o dialéctica, Alonso realiza una resolutio o análisis de los principios de la lógica y de la ciencia en general. Por eso el nombre de Dialectica resolutio que da a su obra. En esa parte de la lógica se estudiaban los problemas semióticos, epistemológicos y aun metafísicos de la lógica formal, por lo que después fue llamada lógica material, para indicar que era complemento de la anterior. Allí, Alonso trata de la naturaleza de la lógica, del ente de razón que es su objeto, de los predicables y de los predicamentos. Además contiene un amplio estudio sobre los universales y los principios del saber, y termina estudiando los fundamentos de la ciencia.

En la dialéctica o lógica mayor se veían algunos temas relativos a la Eisagoge de Porfirio, a las Categorías de Aristóteles y a los Analíticos posteriores, dado que lo concerniente al Peri hermeneias y a los Analiticos primeros se consideraba tratado en las súmulas. Los Tópicos y los Elencos se reservaban para sendos apéndices. Esto último es claro en el caso de Alonso de la Vera Cruz.

Así, el primer tratado que compone su dialéctica es el de la predicabilidad, correspondiente a la Eisagoge. Venía después el tratado de la predicación en concreto, o de los principales tipos de predicado, a saber, los predicamentos, tema contemplado en las Categorías. Y, por último, exponía la teoría de la demostración científica, relativa a los Analíticos posteriores.

Dentro de su dialéctica, en el comentario a la Eisagoge de Porfirio, Alonso estudia el universal lógico. El universal es el concepto, y éste es el instrumento del raciocinio, a través del enunciado. Asimismo, lo universal corresponde principalmente al ente de razón, que es el objeto de la dialéctica o lógica. Los entes de razón son producto de las operaciones de la mente, y la primera operación produce el concepto, esto es, el universal, y por eso Vera Cruz lo estudia como el punto de partida de la lógica. Determina que su status ontológico es el de una entidad mental o pensada (ente de razón), un concepto de la mente que se expresa en el término como en su signo. ${ }^{8}$ Lo divide en los cinco universales o predicables, que eran llamados quinque voces, y que Porfirio trataba en su

\footnotetext{
${ }^{8}$ Véase M. Beuchot, 1984, pp. 249-273; también recogido en W. Redmond y M. Beuchot, 1987, pp. 35-51.
} 
Eisagoge o introducción. Alonso estudia cómo el universal es conocido y producido por el intelecto, mediante la abstracción y la comparación intelectivas. Comprender la naturaleza y la función del universal en el pensamiento hace comprender la lógica misma, ya que sólo así se podrán entender los tres modi sciendi o modos de saber, objetivo o finalidad de la lógica, que son: la definición, la división o proposición y la argumentación. Ya que se usa en los modos de saber, y éstos conforman toda la lógica, es preciso definir lo mejor posible el universal.

Un tema dialéctico sobresaliente es, primeramente, el de lo sujetable y lo predicable, a saber, los elementos que pueden fungir como sujetos o como predicados en las proposiciones o enunciados. Son las palabras las que desempeñan el papel de sujetos y predicados, mas lo hacen porque se refieren a las cosas, a las realidades, en última instancia.

Tras la predicabilidad viene el tratado de la predicación, que versa especialmente sobre las categorías, que son los géneros supremos de predicados o modos de conocer. Primero se tocaban, en una breve sección, los modos de la predicación o del predicarse, llamados antepredicamentos. Eran la univocidad, la equivocidad, la analogía y la denominación. Luego se pasaba a los predicados más generales, es decir, los predicamentos o categorías propiamente dichos, que eran los diez que enumeraba Aristóteles: la sustancia y los nueve accidentes, esto es, cantidad, cualidad, relación, acción, pasión, lugar, tiempo, posición y hábito. Se terminaba este tratado con la sección de los postpredicamentos, que son las relaciones que tienen las categorías entre sí, por ejemplo anterioridad, simultaneidad, oposición, etcétera. ${ }^{9}$

Alonso afronta la cuestión del fundamento de este cuadro categorial, a saber, cómo se basa en la realidad, si es que lo hace, o si es arbitrario y qué tanto. Es la pregunta de si ese cuadro categorial es natural o artificial, o si es una mezcla de ambas cosas, y, en este último caso, cuál de ellas predomina. Alonso también se plantea el problema de la objetividad o subjetividad de las categorías, es decir, si el hombre las percibe directamente o según la relatividad de la cultura, del lenguaje y del esquema conceptual que ha recibido. Los platónicos dicen que las categorías corresponden directamente a la realidad, que son naturales; los nominalistas, que todas las categorializaciones posibles son puramente arbitrarias.

\footnotetext{
${ }^{9}$ Véase M. Beuchot, 1992, pp. 13-24; también recogido en W. Redmond y M. Beuchot, op. cit., pp. 101-116.
} 
Otra vez Alonso adopta una postura intermedia, según la cual se acepta con los platónicos que es posible un orden categorial dado de alguna manera en la naturaleza, pero se añade, con los nominalistas, que no se capta a priori sino a posteriori, sin que por ello sea una construcción arbitraria y puramente cultural.

En su exposición de la teoría aristotélica de la ciencia, Alonso nos habla de ella como el conocimiento por demostración. Expone los distintos tipos de demostración en los que Aristóteles efectuaba su división, poniendo, por una parte, la demostración del hecho o demostración quia y, por otra, la demostración explicativa de la causa, o demostración propter quid, que es la más exigente, y que sólo se puede aplicar a la matemática; establece las condiciones o criterios de sus premisas y conclusiones, haciendo énfasis especialmente en las características epistémicas de unas y otras, esto es, en su condición de axiomas y teoremas, así como su rigurosa concatenación inferencial; asimismo, despliega jerárquicamente el cuadro de las ciencias, repartidas en subalternantes y subalternadas.

Por último, son muy útiles los tratados de Alonso acerca de los tópicos y los sofismas o falacias. ${ }^{10}$ Todo ello pertenece a su enseñanza filosófica, específicamente lógica. Alonso era muy competente en su labor docente, la cual entregaba a los que se preparaban para iniciar el saber filosófico en México, con una excelencia digna de las mejores escuelas europeas. Esa calidad la dejó fray Alonso en el origen del pensamiento filosófico mexicano, en su vertiente o modalidad europea, escolástica y humanista.

\section{La física}

Se pasa entonces a su Physica speculatio, a saber, la especulación o contemplación física, que, además de los consabidos tratados de física aristotélica, contiene elementos de cosmografía y astronomía. En efecto, en su Physica, Alonso aborda la naturaleza de esta disciplina filosófica; pasa a su objeto propio, que es el ser corpóreo; luego al movimiento y sus clases, al espacio y al tiempo. Asimismo, comenta el De caelo, el De meteoris, el De generatione et corruptione y el De anima, que estudia a los seres vivientes, especialmente al hombre. Este último tratado es muy importante, pues no sólo atiende a los sentidos y los aspectos sensitivos

\footnotetext{
${ }^{10}$ Véase M. Beuchot, 1989a, pp. vii-liii y 1989b, vii-xxxii; recogido también en W. Redmond y M. Beuchot, op. cit., pp. 117-196.
} 
del ser humano, sino al intelecto, la razón y la vida del espíritu, sin eludir cuestiones difíciles como la inmortalidad del alma, relacionada con la problemática del entendimiento agente, tan célebre en esa época. ${ }^{11}$

También cabe decir que el De caelo es una obra científica de fray Alonso, uno de los primeros productos de la ciencia americana, que nacía en ese momento. Efectivamente, después de estudiar los cielos y los astros, analiza la tierra, con sus diferentes regiones y climas. Igualmente examina las nuevas tierras descubiertas en el Nuevo Mundo. Al respecto, tiene toda una descripción de América; siguiendo los litorales, parte de la Península del Labrador, pasa por la Tierra del Fuego, y después sigue hacia el norte, hasta arribar a lo que ahora conocemos como Estados Unidos. Llega un momento en que suspende su descripción, diciendo que allí siguen tierras que nadie conoce, por estar todavía inexploradas. Esto constituye una aportación científica en los orígenes de la ciencia americana, producto de su conversación con capitanes y marinos que habían participado en esas exploraciones y descubrimientos.

\section{La filosofía jurídica}

Dentro del campo de la filosofía jurídica, se encuentran obras que de suyo eran pensadas como teológicas, o como de derecho canónico; por ejemplo, el De decimis (sobre los diezmos), el De dominio infidelium y el Speculum coniugiorum. Este último es un dechado de filosofía práctica que expone el ideal de fray Alonso para la pareja humana, la ética y la teología moral aplicadas al matrimonio y la defensa de la unidad familiar. En esa obra se destacan los apartados que Alonso dedica al tema del consentimiento, al de la separación de los cónyuges y a las dificultades que traía consigo el matrimonio entre indígenas (ya que había poligamia y otras situaciones que resultaban problemáticas para los misioneros). Además de esas doctrinas filosóficas y teológicas relativas a la moral, esta obra ha sido considerada como una aportación a la antropología, por la descripción de costumbres indígenas en lo relativo al matrimonio.

En cuanto a las doctrinas filosófico-jurídicas pertinentes a la situación política del Nuevo Mundo, Antonio Gómez Robledo ${ }^{12}$ llega a comparar a fray Alonso con Vitoria por su fuerza doctrinal, y, por otro lado, afirma que no fue un defensor del indio menos apasionado que Las Ca-

${ }^{11}$ Véase M. Beuchot, 1986, pp. 11-24, y W. Redmond y Beuchot, op. cit., pp. 19-33.

${ }^{12}$ Véase A. Gómez Robledo, 1984; véase también E. J. Burrus, 1968. 
sas, sólo que su actividad en pro de la justicia no fue tan notoria como la del obispo de Chiapas. Muchas son las cosas que nos hablan de la excelencia de la doctrina jurídica escolástica contenida en su obra $D e$ dominio infidelium. En la línea de Vitoria —su maestro—y los teólogos salmantinos, Vera Cruz piensa que la soberanía procede del pueblo y que el gobernante se vuelve un dictador por el modo como sube al poder (tyrannus ab origine o a titulo) y por la manera de gobernar o regir (tyrannus a regimine). Cualquiera de los dos títulos hace al gobernante injusto merecedor de ser depuesto. Además, Vera Cruz niega que haya siervos por naturaleza, en consecuencia con lo cual el dominio sobre los indios (por el rey y los encomenderos) depende de la voluntad popular y no pueden poseerse sus tierras, ya que los naturales ni siquiera por su infidelidad o paganismo pierden el derecho a poseerlas. Esta doctrina era sumamente dura y valiente, aunque ya por ese tiempo estaba muy avanzada la conquista y no se podía dar marcha atrás.

Fray Alonso muestra ser discípulo de Vitoria al exigir que se dé doctrina a los indígenas, ya sean éstos recibidos legítimamente o no por los encomenderos. Asimismo, dice con toda determinación que los legítimos dueños de esas tierras eran los indios. John Wiclef había sostenido que el dominio de las cosas se perdía por el pecado mortal, pero la escuela tomista se opuso a ello; más aún, consideraba que los indios no tenían pecado de infidelidad, porque ni siquiera habían oído de la fe cristiana, y por eso eran legítimos dueños, y su dominio les fue quitado con injusticia. Vera Cruz no acepta el dominio universal del emperador, como lo defendía Miguel de Ulzúrrum, ni el del papa, como sostenía el Ostiense; por lo cual ninguno les pudo quitar a los indios sus tierras y su derecho a gobernar, ya que ni el emperador ni el papa podían despojarlos de sus imperios. Hay, sin embargo, una cosa desconcertante en la doctrina de Vera Cruz, y es que admite que el papa puede comisionar al emperador para el bien espiritual, o puede darle alguna parte del mundo para que la haga evangelizar. Aquí fray Alonso está cayendo en la nefasta doctrina del poder temporal indirecto de la Iglesia: no es el papa el que asume la imposición de la fe, sino que la comisiona al emperador, que es el jefe temporal.

De manera semejante a Vitoria, Vera Cruz enumera los títulos ilegítimos que se aducían para la conquista, así como los que se pueden alegar como legítimos - aunque las listas de uno y otro difieren un tanto. Los títulos ilegítimos que establece Alonso son los siguientes: (i) la infidelidad de los indios; (ii) la pertenencia de iure del nuevo mundo al antiguo 
Imperio romano; (iii) los agravios de los indios a los españoles; (iv) la oposición de los indios a la predicación del evangelio; (v) la renuencia de los indios a abrazar la fe; (vi) los pecados contra naturam de los indios; (vii) el atraso mental y la "amencia" de los indios, y (viii) la conquista por orden de Dios. De acuerdo con ello, los que se basan en estos títulos no alcanzan a legitimar la conquista. En cambio, Vera Cruz aduce los siguientes títulos que sí legitiman, según él, la conquista de los indios, aunque no el modo como se llevó a cabo: (i) la obligación que tienen los nativos de recibir la fe, y al cumplimiento de cuyas exigencias puede compelerlos el emperador; (ii) la misma obligación, a cuyo cumplimiento puede compelerlos el romano pontífice; (iii) el dar un príncipe cristiano a los conversos; (iv) el régimen tiránico de los príncipes bárbaros, que debe evitarse; (v) la antropofagia y los sacrificios humanos; (vi) las alianzas entre los españoles y otros pueblos indígenas, como los tlaxcaltecas; (vii) la elección libre y voluntaria de los indios, y (viii) el ius communicationis et commercii, con otros derechos anexos o derivados.

\section{Conclusión}

En la base de la enseñanza de Alonso de la Vera Cruz está la doctrina aristotélico-tomista, pero también conoce las nuevas teorías humanistas y renovadoras de su época. Por eso, junto con su preocupación didáctica, se nota una lucha por integrar las innovaciones filosóficas, tanto nominalistas posmedievales como humanistas renacentistas, participando en la renovación intelectual. ${ }^{13}$ Así, además de su conocimiento de la tradición aristotélico-tomista, se puede señalar en su obra el influjo de los neoterici, nombre que se daba tanto a los nominalistas posmedievales como a los humanistas del Renacimiento. Fue fiel discípulo de Vitoria en Salamanca y siguió muy de cerca a Soto, pero también se nota el intento de asimilar nuevas doctrinas provenientes de filósofos humanistas, y no únicamente el afán de copiar su estilo. Todo eso lo incorpora en su enseñanza de manera sistemática y crítica.

Dada su preocupación didáctica, fray Alonso no tiene como interés principal la originalidad; pero, aun así, llega a hacer aportaciones considerables. Ya en el ámbito de la docencia, su obra es muy meritoria,

${ }^{13}$ Véase algunas de sus innovaciones en M. Beuchot y E. González Ruiz, 1985, pp. 221-233. 
por ser la semilla filosófica sembrada en las nuevas tierras descubiertas. Ciertamente enseña el pensamiento escolástico, pero no es un mero repetidor; trata de mejorar y purificar muchas doctrinas, y sobre todo el método de enseñanza, quitándole los elementos con los que lo habían recargado muchos escolásticos de su momento. Todo ello habla de su talento como pensador.

No solamente fue el primero en enseñar filosofía a los pensadores mexicanos de ese entonces, tanto españoles como criollos, sino también a los indígenas. En efecto, tuvo entre sus alumnos a don Antonio Huirziméngari Mendoza y Calzonzin, hijo del último cacique de los tarascos. Esto lo coloca, pues, como uno de los pioneros en la formación del pensamiento filosófico y teológico de las nuevas tierras, en la línea de la filosofía europea, concretamente escolástica, no sólo en las escuelas de los agustinos, sino en la recién fundada Universidad de México. Y, sobre todo, porque enfrentó problemas candentes en su momento, como el de la conquista, el de los tributos, el de los diezmos, el de los matrimonios indígenas, etcétera.

\section{BIBLIOGRAFÍA}

Beuchot, M., "El problema de los universales en Domingo de Soto y en Alonso de la Vera Cruz", Revista de Filosofía, 17, 1984, pp. 249-273.

_, "Introducción", en fray Alonso de la Vera Cruz, 1989a, pp. vii-liii.

_, "Introducción", en fray Alonso de la Vera Cruz, 1989b, pp. vii-xxxii.

_, "La antropología filosófica de Alonso de la Vera Cruz", en AA. vv., Homenaje a fray Alonso de la Veracruz en el IV centenario de su muerte (1584-1984), México, unAM, 1986, pp. 11-24.

_, "Lógica y dialéctica en fray Alonso de la Vera Cruz", en M. Beuchot y B. Navarro (comps.), Dos homenajes: Alonso de la Vera Cruz y Francisco Xavier Clavigero, México, UNAM, 1992, pp. 13-24.

_, y E. GonZÁlez RuIz, "La falacia de petición de principio en fray Alonso de la Vera Cruz”, Noua Tellus, 3, 1985, pp. 221-233.

Bolaño e Isla, A., Contribución al estudio bibliográfico de fray Alonso de la Vera Cruz, México, Robredo-Porrúa, 1947.

Burrus, E. J., The Writings of Alonso de la Vera Cruz, 5 vols., Roma / Saint Louis Missouri, 1968.

Cerezo de Diego, P., Alonso de Veracruz y el derecho de gentes, México, Porrúa, 1985.

Gallegos Rocafull, J. M., El pensamiento mexicano de los siglos XVI y XVII (2 ed.), México, unAm, 1974.

_, "La filosofía en México en los siglos XVI y XVII", en AA. VV., Estudios de historia de la filosofía en México (3 ${ }^{\mathrm{a}}$ ed.), México, UnAM, 1973 pp. 109-144. 
Gómez Robledo, A., El magisterio filosófico y jurídico de Alonso de la Vera Cruz, México, Porrúa, 1984.

Redmond, W., Bibliography of the Philosophy in the Iberian Colonies of America, The Hague, Martinus Nijhoff, 1972.

_, "Relations and $16^{\text {th }}$ Century Mexican Logic", Crítica, 22, 65, 1984, pp. 23-41.

_, у М. BЕUсHOt, La lógica mexicana en el siglo de oro, México, UnAM, 1985.

_, y M. Beuchot, Pensamiento y realidad en fray Alonso de la Vera Cruz, MéxiCO, UNAM, 1987.

UlzÚRrum, Miguel de, Catholicum opus imperiale regiminis mundi, Zaragoza, 1525.

Vera Cruz, Alonso de la, Libro de los elencos sofísticos, introducción, transcripción y notas de Mauricio Beuchot, México, unAm, 1989a (Bibliotheca Philosophica Latina Mexicana, 1).

_, Tratado de los tópicos dialécticos, introducción, transcripción y notas de Mauricio Beuchot, México, UnAm, 1989b (Bibliotheca Philosophica Latina Mexicana, 3).

_, De dominio infidelium et iusto bello, I-II, introducción, transcripción y notas de Roberto Heredia Correa, México, UnAM, 2000 (Bibliotheca Philosophica Latina Mexicana, 13). 